\title{
Open Thoracoabdominal Aortic Aneurysm Repair in Cardiopulmonary Testing Era: A Correlative Cohort Analysis
}

\author{
Damian Bailey ${ }^{1}$, Claire Halligan ${ }^{2}$, Richard Davies ${ }^{3}$, Anthony Funnell ${ }^{4}$, Ian Appadurai ${ }^{3}$, \\ George Rose $^{1}$, Lara Rimmer ${ }^{5}$, Matti Jubouri ${ }^{6}$, Joseph Coselli ${ }^{7}$, Ian Williams ${ }^{3}$, and \\ Mohamad Bashir ${ }^{1}$ \\ ${ }^{1}$ University of South Wales Faculty of Life Sciences and Education \\ ${ }^{2}$ Wrexham Maelor Hospital \\ ${ }^{3}$ University Hospital of Wales \\ ${ }^{4}$ Princess of Wales Hospital \\ ${ }^{5}$ Health Education England North West \\ ${ }^{6}$ Hull York Medical School \\ ${ }^{7}$ Baylor College of Medicine Michael E DeBakey Department of Surgery
}

February 15, 2022

\begin{abstract}
Background: Initial clinical evaluation (ICE) is traditionally considered a useful screening tool to identify frail patients during the pre-operative assessment. However, emerging evidence supports the more objective assessment of cardiorespiratory fitness $(\mathrm{CRF})$ via cardiopulmonary exercise testing (CPET) to improve surgical risk stratification. Herein, we compared both subjective and objective assessment approaches to highlight the interpretive idiosyncrasies. Methods: As part of routine pre-operative patient contact, patients scheduled for major surgery were prospectively 'eyeballed' (ICE) by two experienced clinicians prior to more detailed history taking that also included American Society of Anaesthesiologists score classification. Each patient was subjectively judged to be either 'frail' or 'not frail' by ICE and 'fit' or 'unfit' from thorough review of the medical notes. Subjective data were compared against the more objective validated assessment of post-operative outcomes using established CPET 'cut-off' metrics incorporating peak pulmonary oxygen uptake ( $\left.V \mathrm{O}_{2 \mathrm{PEAK}}\right), V \mathrm{O}_{2}$ at the anaerobic threshold ( $V \mathrm{O}_{2-}$ $\mathrm{AT}$ ) and ventilatory equivalent for carbon dioxide that collectively informed risk stratification. These data were retrospectively extracted from a single-centre prospective National Health Service database. Data were analysed using the Chi-square automatic interaction detection decision tree method. Results: A total of 127 patients examined that comprised $58 \%$ male and $42 \%$ female patients aged $69 \pm 10 \mathrm{y}$ with a BMI of $29 \pm 7 \mathrm{~kg} / \mathrm{m}^{2}$. Patients were poorly conditioned with a peak pulmonary oxygen uptake almost $20 \%$ lower than that predicted for age, sex-matched healthy controls with $35 \%$ exhibiting a $V O{ }_{2}$-AT $<11$ $\mathrm{mL} / \mathrm{kg} / \mathrm{min}$. Disagreement existed between the subjective assessments of risk with $\sim 34 \%$ of patients classified not frail on ICE were considered unfit by notes review $(P<0.0001)$. Furthermore, $\sim 35 \%$ of patients considered not frail on ICE and $\sim 31 \%$ of patients considered fit by notes review exhibited a $V \mathrm{O}_{2}-\mathrm{AT}<11 \mathrm{~mL} / \mathrm{kg} / \mathrm{min}$ and of these, $\sim 28 \%$ and $\sim 19 \%$ were classified as intermediate-to-high risk. Conclusions: These findings highlight the interpretive limitations associated with the subjective assessment of patient frailty with surgical risk classification underestimated in up to a third of patients compared to the validated assessment of CRF. They reinforce the benefits of a more objective and integrated approach offered by CPET that may help improve perioperative risk assessment and better direct critical care provision in patients scheduled for 'high-stakes' surgery including open TAAA repair.
\end{abstract}

Open Thoracoabdominal Aortic Aneurysm Repair in Cardiopulmonary Testing Era: A Correlative Cohort Analysis 
Damian M. Bailey ${ }^{*}$, Claire L. Halligan ${ }^{2}$, Richard G. Davies ${ }^{3}$, Anthony Funnell ${ }^{4}$, Ian R. Appadurai ${ }^{3}$, George Rose $^{1}$, Lara Rimmer ${ }^{5}$, Matti Jubouri ${ }^{6}$, Joseph S. Coselli ${ }^{7,8,9}$, Ian M. Williams ${ }^{10}$, Mohamad Bashir ${ }^{1,10}$

${ }^{1}$ Neurovascular Research Laboratory, Faculty of Life Sciences and Education, University of South Wales, Pontypridd, UK $;{ }^{2}$ Department of Anaesthesia, Wrexham Maelor Hospital, Wrexham, UK; ${ }^{3}$ Department of Anaesthetics, University Hospital of Wales, Cardiff, UK; ${ }^{4}$ Department of Anaesthetics, Princess of Wales Hospital, Velindre University NHS Trust, Health Education \& Improvement Board Wales (HEIW), Wales, UK $;^{5}$ North West School of Surgery, Health Education England North West, Manchester, UK; ${ }^{6}$ Hull York Medical School, University of York, York, UK; ${ }^{7}$ Division of Cardiothoracic Surgery, Michael E. DeBakey Department of Surgery, Baylor College of Medicine, USA ${ }^{8}$ Department of Cardiovascular Surgery, Texas Heart Institute, USA and ${ }^{9}$ Department of Cardiovascular Surgery, CHI St Luke's Health-Baylor St Luke's Medical Center, Houston, Texas, USA and ${ }^{10}$ Department of Surgery, University Hospital of Wales, Cardiff, UK

Keywords: thoracoabdominal; aorta; aneurysm; cardiopulmonary exercise testing; frailty; fitness

\section{Sources of Funding and Conflict of Interest}

This work was supported by a Royal Society Wolfson Research Fellowship (\#WM170007) and funding from the Higher Education Funding Council for Wales (to Prof. DM Bailey). Prof. DM Bailey is a member of the Cardiovascular Network for Wales. Dr. JS Coselli participates in clinical trials with and/or consults for Terumo Aortic, Medtronic, and W.L. Gore \& Associates and receives royalties and grant support from Terumo Aortic. The remaining authors report no disclosures. The authors have no competing interests to declare.

\section{*Correspondence}

Professor Damian M. Bailey PhD FPVRI FRSC FACSM FTPS

Royal Society Wolfson Research Fellow

Professor of Physiology \& Biochemistry

Director of the Neurovascular Research Laboratory

Faculty of Life Sciences and Education

Alfred Russel Wallace Building

University of South Wales

\section{UK CF37 4AT}

damian.bailey@southwales.ac.uk

\section{Abbreviations}

Cardiopulmonary exercise testing (CPET)

Initial clinical evaluation (ICE)

Peak oxygen uptake ( $\left.V \mathrm{O}_{2 \mathrm{PEAK}}\right)$

Ventilatory equivalent for carbon dioxide $\left(V \mathrm{E}_{\mathrm{E}} / V \mathrm{CO}_{2}\right)$

Oxygen uptake efficiency slope (OUES)

Pulmonary oxygen uptake at the anaerobic threshold $\left(V \mathrm{O}_{2}\right.$-AT)

BMI (body mass index)

FVC (forced vital capacity) 
$\mathrm{FEV}_{1}$ (forced expiratory volume in one second)

ASA (American Society of Anaesthesiologists score)

\begin{abstract}
Background: Initial clinical evaluation (ICE) is traditionally considered a useful screening tool to identify frail patients during the pre-operative assessment. However, emerging evidence supports the more objective assessment of cardiorespiratory fitness (CRF) via cardiopulmonary exercise testing (CPET) to improve surgical risk stratification. Herein, we compared both subjective and objective assessment approaches to highlight the interpretive idiosyncrasies.

Methods: As part of routine pre-operative patient contact, patients scheduled for major surgery were prospectively 'eyeballed' (ICE) by two experienced clinicians prior to more detailed history taking that also included American Society of Anaesthesiologists score classification. Each patient was subjectively judged to be either 'frail' or 'not frail' by ICE and 'fit' or 'unfit' from thorough review of the medical notes. Subjective data were compared against the more objective validated assessment of post-operative outcomes using established CPET 'cut-off' metrics incorporating peak pulmonary oxygen uptake $\left(V \mathrm{O}_{2 \mathrm{PEAK}}\right), V \mathrm{O}_{2}$ at the anaerobic threshold $\left(\mathrm{V} \mathrm{O}_{2}\right.$-AT) and ventilatory equivalent for carbon dioxide that collectively informed risk stratification. These data were retrospectively extracted from a single-centre prospective National Health Service database. Data were analysed using the Chi-square automatic interaction detection decision tree method.
\end{abstract}

Results: A total of 127 patients examined that comprised $58 \%$ male and $42 \%$ female patients aged 69 \pm 10 y with a BMI of $29 \pm 7 \mathrm{~kg} / \mathrm{m}^{2}$. Patients were poorly conditioned with a peak pulmonary oxygen uptake almost $20 \%$ lower than that predicted for age, sex-matched healthy controls with $35 \%$ exhibiting a $V \mathrm{O}_{2}$-AT $<11 \mathrm{~mL} / \mathrm{kg} / \mathrm{min}$. Disagreement existed between the subjective assessments of risk with $\sim 34 \%$ of patients classified not frail on ICE were considered unfit by notes review $(P<0.0001)$. Furthermore, $\sim 35$ $\%$ of patients considered not frail on ICE and $\sim 31 \%$ of patients considered fit by notes review exhibited a $V \mathrm{O}_{2}-\mathrm{AT}<11 \mathrm{~mL} / \mathrm{kg} / \mathrm{min}$ and of these, $\sim 28 \%$ and $\sim 19 \%$ were classified as intermediate-to-high risk.

Conclusions: These findings highlight the interpretive limitations associated with the subjective assessment of patient frailty with surgical risk classification underestimated in up to a third of patients compared to the validated assessment of CRF. They reinforce the benefits of a more objective and integrated approach offered by CPET that may help improve perioperative risk assessment and better direct critical care provision in patients scheduled for 'high-stakes' surgery including open TAAA repair.

\title{
Background
}

Traditionally, assessment of fitness for surgery involves a surgeon's subjective judgement on whether a patient is sufficiently conditioned to undergo the proposed procedure. Valid and reliable assessment of a person's functional capacity is thus considered an important component of preoperative evaluation ${ }^{1}$. The initial clinical evaluation (ICE) can be a useful screening tool to identify frail patients in the pre-operative assessment, despite limited research to validate implementation. 'Frailty' identifies those patients with a diminished capacity to compensate adequately for external stressors who are at greater risk of adverse outcomes including a prolonged hospital stay, institutionalisation, worsening disability and even death ${ }^{2,3}$. It is important to recognize diminished capacity in patients prior to surgery given that they are less likely to survive or return to functional status following the physiological insult of surgery compared to their fitter, more resilient counterparts ${ }^{4}$.

ICE almost inextricably requires a clinician to make a rapid decision concerning the fitness for an operation based on little more than external appearances. In contrast, preoperative cardiopulmonary exercise testing (CPET) enhances the integrated risk assessment by providing a more objective measure to establish if a patient has adequate cardiorespiratory fitness (CRF) to tolerate major surgery. In support, CPET has gained popularity as part of the routine preoperative diagnostic assessment and its predictive value in relation to mid- and long-term survival in patients undergoing elective open surgical abdominal aortic aneurysm (AAA) repair is well established including its ability to forecast postoperative morbidity ${ }^{5-7}$. 
This is especially relevant for open thoracoabdominal aortic aneurysm (TAAA) surgery, given that it requires careful selection of patients who will be suitable to undergo extensive surgery and lengthy postoperative recovery (Figure 1). Predictive risk models have shown that multi-system impairment is related to negative operative outcomes predisposing to longer recovery times and increased risk of short- and long-term mortality and morbidity ${ }^{8}$. Lung disease, older age, female sex, New York Heart Association's (NYHA) moderate (III) or severe (IV) classifications and reduced left ventricular ejection fraction have been identified as independent risk factors for patients undergoing proximal aortic repair ${ }^{9}$. However, there is no singular metric with the capacity to accurately predict clinical outcome ${ }^{2}$.

Thus, it is suspected that patients with poor CRF are especially vulnerable when faced with the enhanced metabolic demands posed by open TAAA repair and have an unmet need to better guide patient evaluation, risk and clearance for surgery. In the coming years when both open and endovascular options for thoracoabdominal aortic repair are widely available, there will no doubt be a need to objectively evaluate each patient to identify the ideal method of surgical repair.

To that end, the present study sought to compare subjective ICE ('eyeballing') by experienced clinicians against the more objective validated preoperative assessment using formalised CPET metrics for patients undergoing major elective surgery. We hypothesized that subjective assessment would underestimate a patient's 'true' surgical risk, highlighting the benefits of a more integrated objective approach that has direct relevance for patients scheduled for open TAAA repair.

\section{Methods}

\section{Ethical approval}

The Cardiff and Vale University Health Board (15/AIC/6352) approved the retrospective analysis of an anonymised database and thus patient consent was waived. All procedures were carried out in accordance with the Declaration of Helsinki of the World Medical Association ${ }^{10}$.

\section{Design}

Clinical data were extracted from a single-centre (University Hospital of Wales, UK) prospective National Health Service database for the purposes of improving perioperative outcomes in patients scheduled for elective major intra-abdominal surgery over a 12-month period. Data points were captured using a variety of methods, including medical record abstraction and formal data collection (below).

\section{Clinical assessments}

Demographics

Patient data was gathered from medical notes and recorded by the clinician conducting CPET and comprised stature, body mass, derivation of body mass index (BMI) and closed loop flow spirometry.

Subjective assessment

As part of the routine evaluation of patients prior to surgery, patients were clinically assessed by two experienced clinicians (RGD and IRA) to determine frailty and fitness for surgery. The clinical evaluation included the detailed collection of a patient-specific medical history. This clinical determination aimed to answer the question "Is this patient attending for clinical assessment today fit enough for the proposed surgical procedure?" Each patient was judged to be either 'frail' or 'not frail' after the initial meeting, and this was supplemented with "fit" or "not fit" from careful review of their medical notes. Patients were also graded according to the American Society of Anaesthesiologists (ASA) grading criteria ${ }^{11}$ whereby a healthy patient is ASA I, a patient with mild systemic disease is ASA II, a patient with severe systemic disease is ASA III, ASA IV refers to a patient with life-threatening severe systemic disease and ASA V to a moribund patient.

Objective assessment 
CPET: Pre-operative CPET was conducted using an electromagnetically braked cycle ergometer (Lode, Gronigen, The Netherlands) and a Medgraphics Ultima metabolic cart (MedGraphics ${ }^{\mathrm{TM}}$, Gloucester, UK) as previously outlined by our group ${ }^{7,12,13}$. Briefly, calibration was undertaken in accordance with the manufacturer's guidelines using a 3-L volume syringe (Hans Rudolph, Kansas City, USA) and reference calibration gases. During data collection, the middle five of seven breaths were averaged. An exercise protocol was employed requiring patients to cycle at 60 revolutions per minute for three minutes in an unloaded freewheeling state followed by a progressively ramped period of exercise (5 to $15 \mathrm{~W} / \mathrm{min}$ based on mass, stature, age, and sex) to volitional or symptom limited termination, followed by three minutes recovery ${ }^{14}$. Medgraphics Breeze ${ }^{\mathrm{TM}}$ software automatically determined peak oxygen uptake $\left(V \mathrm{O}_{2 \operatorname{PEAK}}\right)$ (defined as the highest $V \mathrm{O}_{2}$ during the final 30 seconds of exercise reported), the slope of the relationship between pulmonary ventilation and carbon dioxide output $\left(V_{\mathrm{E}} / V \mathrm{CO}_{2}\right)$ and oxygen uptake efficiency slope (OUES). Pulmonary oxygen uptake at the anaerobic threshold $\left(V \mathrm{O}_{2}\right.$-AT) was manually interpreted by an experienced clinician using the $\mathrm{V}$-slope method ${ }^{15}$, supported by $V \mathrm{E} / V \mathrm{CO}_{2}$-AT, and $V$ E $/ V \mathrm{O}_{2}$-AT.

Risk classification: Each patient was classified with a $V \mathrm{O}_{2}$-AT below $(<)$ or above $\left.(>) 11 \mathrm{~mL} \mathrm{O}_{2} / \mathrm{kg} / \mathrm{min}\right)$ based on the seminal works of Weber and Janicki ${ }^{16}$ and Older et al. ${ }^{17}$ We further differentiated between low, intermediate and high risk according to the following criteria:Low risk : $V \mathrm{O}_{2}$-AT [?]11 $\mathrm{mL} / \mathrm{kg} / \mathrm{min} ;$ Intermediate risk : One of: $V \mathrm{O}_{2}$-AT $8-10.9 \mathrm{~mL} / \mathrm{kg} / \mathrm{min}, V \mathrm{E}_{\mathrm{E}} / V \mathrm{CO}_{2}$-AT $>34$, history of ischaemic heart disease (IHD); High risk : $V \mathrm{O}_{2}-\mathrm{AT}<8 \mathrm{~mL} / \mathrm{kg} / \mathrm{min}$ or [?]two of: $V \mathrm{E} / V \mathrm{CO}_{2}-\mathrm{AT}>34, V$ $\mathrm{O}_{2}-\mathrm{AT}<11 \mathrm{~mL} / \mathrm{kg} / \mathrm{min}$, history of IHD.

\section{Statistical analyses}

Statistical analyses were undertaken using IBM SPSS Statistics for Windows (Version 27.0, IBM, Armonk, NY, USA). Continuous variables are reported as mean \pm standard deviation (SD). Categorical variables are reported as frequencies with percentages. Categorical comparisons were conducted using $\chi^{2}$ tests and $\chi^{2}$ automatic interaction detection decision tree method.

\section{Results}

\section{Patient characteristics}

Table 1 summarises patient characteristics including demographics and cardiopulmonary performance (spirometry and CPET) with a total of 127 patients examined. Thirty-nine patients $(31 \%$ ) were classified as obese with fifty-six (44\%) overweight. As anticipated, these patients were poorly conditioned with a $V \mathrm{O}_{2 \mathrm{PEAK}}$ that was on average almost $20 \%$ lower than that predicted for age, sex-matched healthy controls with forty-five patients $(35 \%)$ exhibiting a $V \mathrm{O}_{2}$-AT $<11 \mathrm{~mL} / \mathrm{kg} / \mathrm{min} . V \mathrm{O}_{2}$-AT could not be determined in eighteen patients (14\%).

\section{Clinical risk assessments}

Figure 2 illustrates patient distribution of clinical risk classification according to assessment method providing a visual of the (dis) agreements observed complemented by the CHAID decision tree method analyses summarised in Figures 2-3.

Subjective: There was clear disagreement between the subjective assessments of risk (ICE-Eyeball (Frailty) compared to Notes Review (Fitness) with $\sim 34 \%$ of patients classified not frail considered unfit by notes review (Figure $3 \mathrm{~A}$ ). Equally, $\sim 88 \%$ of patients considered not frail and $\sim 82 \%$ of patients considered fit by ICE (Figure $3 \mathrm{~B}$ ) and notes review (Figure $3 \mathrm{C}$ ) respectively were classified ASA Grade II-III (mild to severe disease).

Objective: Subjective assessments generally underestimated patient risk compared to objective CPET criteria ( $V \mathrm{O}_{2}-\mathrm{AT}<11 \mathrm{~mL} / \mathrm{kg} / \mathrm{min}$ and intermediate-to-high risk). Indeed, $\sim 35 \%$ of patients considered not frail on ICE and $\sim 31 \%$ of patients considered fit by notes review exhibited a $V \mathrm{O}_{2}$-AT $<11 \mathrm{~mL} / \mathrm{kg} / \mathrm{min}$ (Figure $4 \mathrm{~A}-\mathrm{B}$ ). Of these, $\sim 28 \%$ and $\sim 19 \%$ (not frail and fit patients respectively) were classified as intermediateto-high risk by CPET criteria (Figure 4 C-D). 


\section{Discussion}

By comparing subjective clinical evaluation of a patient's risk by experienced clinicians against the more objective validated assessment of post-operative outcomes via CPET, the present study has identified two important findings. First, we identified clear disagreement between subjective assessments of risk with a third of patients classified not frail considered unfit by notes review and almost nine out of ten patients suffering from mild to severe disease by ASA classification. Second, and consistent with our original hypothesis, subjective assessment underestimated surgical risk in up to a third of patients. Collectively, these findings highlight the benefits of a more objective and integrated approach offered by CPET that may help improve perioperative risk assessment and direct care provision in patients scheduled for 'high-stakes' open TAAA repair.

\section{Surgical demands}

Surgery is the third largest cause of death after ischaemic heart disease and stroke accounting for almost $8 \%$ of all deaths globally ${ }^{18}$. Given the ageing population and projected burden of vascular arterial occlusive/aneurysmal disease, surgery remains a major concern for healthcare providers. Importantly, the "high risk' surgical patient accounts for $13 \%$ of cases yet contributes to a disproportionate $>80 \%$ of all postoperative deaths and complications ${ }^{19}$. This is especially the case for TAAA patients given the extensive repair required and prolonged recovery time with increasing interest direct towards the 'gold-standard' assessment of CRF via CPET to provide more objective insight into surgical risk stratification.

An adequate, albeit presently undefined CRF conferring improved physiological reserve is required in order for a patient to tolerate extensive open TAAA repair, given that single lung ventilation is obligatory in order to expose the thoracic aorta following collapse of the left lung (Figure 1). Acceptable preoperative spirometry assessment of the pulmonary circulation may consist of an $\mathrm{FEV}_{1}>1 \mathrm{~L}$ and arterial partial pressure of carbon dioxide $<45 \mathrm{mmHg}^{19}$. Postoperative pulmonary complications and reintubation rates of up to $15 \%$ in the highest volume centres indicate that this remains a major cause of morbidity following TAAA surgery ${ }^{20}$. Pulmonary complications occur in up to $36 \%$ of patients and any adverse lung function tests preoperatively, highlighted through spirometry and arterial blood gas analysis, may be advised to undergo a regime including physical exercise, spirometry training and bronchodilator therapy ${ }^{21}$. Other factors reducing prolonged ventilator support included preservation of the central tendon of the diaphragm by circumferential division and avoidance of excessive blood products ${ }^{22}$. Postoperatively, adequate pulmonary function is essential for perioperative survival as all patients will be intubated in the immediate and extensive postoperative recovery phase.

\section{Patient co-morbidities}

Importantly, many patients undergoing TAAA repair will have pre-existing coronary artery disease (CAD) and associated risk factors ${ }^{20}$. Significant (but possibly silent) cardiac disease may reduce patient tolerance of thoracic aortic cross-clamping, an obligatory procedure that immediately increases afterload, and left ventricular stress, upon the heart ${ }^{21}$. Oxygen deprivation in proximal tissues and sympathoadrenal discharge constricts arterioles and is typically accompanied by arteriovenous shunting. Whilst acute (CPET) exercise may not replicate the profound physiological challenges imposed by cross-clamping, assessing the patient's body under 'simulated' (physical) stress and corresponding systemic response to microcirculatory hypoxaemia may determine how well systemic tissue perfusion adapts to the surgical insult.

Furthermore, there is mounting evidence that the risk of developing spinal cord ischaemia is increased by up to $80 \%$ in those with $\mathrm{CAD}^{23}$. Identification of disease may not negate surgery but may lead to optimisation by coronary artery stenting or instigating antiplatelet therapy prior to any planned procedure ${ }^{21,24}$. Connective tissue disorders represent an additional major risk factor for thoracic aortic disease with up to $20 \%$ of patients expressing at least one 'high-risk' gene ${ }^{25}$. Marfan syndrome (MS) is one such genetic disorder and typically presents in younger patients ${ }^{26}$. Giske et al. focused on pulmonary function and rehabilitation in patients with MS and found that $V \mathrm{O}_{2 \mathrm{PEAK}}$ was $30 \%$ and $50 \%$ lower in females and males respectively, compared to healthy (non-MS) controls ${ }^{27}$. 


\section{TAAA surgery and CPET}

While there is clear justification for the integration of CPET into perioperative risk assessment for open TAAA, there are surprisingly few studies in the published literature. Hornsby et al . used CPET postoperatively only to assess exercise tolerance following open TAAA or type A dissection repair ${ }^{28}$. CPET was analysed retrospectively or performed three months following open repair and identified that (median) $V$ $\mathrm{O}_{2 \text { PEAK }}$ was reduced by $36 \%$ after type $\mathrm{A}$ aortic dissection repair. This highlights the critical increase in metabolic demand driven by the need to increase vascular $\mathrm{O}_{2}$ delivery to support the additional cellular bioenergetic demands incurred by surgery to ensure successful recovery ${ }^{29}$. If the patient is unable to fulfil this metabolic demand (i.e. CRF is inadequate), the physiological 'insult' posed by TAAA surgery can subsequently lead to $\mathrm{O}_{2}$ debt that can overwhelm the patient and result in organ failure and death ${ }^{30}$.

In the present study, we chose to differentiate between those patients with and without 'adequate' CRF based on the 'cut-off' metrics originally established by Weber and Janicki ${ }^{16}$ in heart failure patients and later implemented by Older et al. ${ }^{17}$ specifically $V \mathrm{O}_{2}$-AT $<$ (unfit) or $>$ (fit) $11 \mathrm{~mL} / \mathrm{kg} / \mathrm{min}$. Older et al. ${ }^{17}$ identified an $18 \%$ mortality rate in elderly surgical patients considered unfit by this threshold compared to $0.8 \%$ in fit patients. We further categorised patients based on CPET risk through additional implementation of complementary biomarkers including $V \mathrm{O}_{2}$ peak $<15 \mathrm{~mL} / \mathrm{kg} / \mathrm{min}$ and $V \mathrm{E}_{\mathrm{E}} / V \mathrm{CO}_{2}$ - $\mathrm{AT}>34$ given their combined ability to distinguish the 'at-risk' patient and better predict post-operative survival following AAA surgery $^{31}$. However, it is important to emphasise that ongoing research continues to better define threshold metrics to further optimise risk prediction models and this is especially relevant for TAAA patients given the magnitude of the surgical 'hit' encountered. Furthermore, CRF (and corresponding risk) stratification needs to be based not on a single binary cut-off but rather a range of values for any given dynamic CPET metric given the inherent (and extensive) biological variation ${ }^{13}$ and this remains to be established for the 'high-stakes' TAAA patient.

Importantly and in stark contrast to the present study, none of these researchers have reported the clinician's initial views prior to surgery. There are understandable if not unavoidable limitations to what a clinician might gain from the very first review of a patient, often without a thorough knowledge of past medical history. Initial information is oftentimes dictated by loose 'impressions' of cognitive function, body habitus, strength of handshake and general nutritional status ${ }^{32}$. Our findings highlight that ICE is indeed unreliable compared to CPET metrics with the danger of underestimating patient risk. This has implications when determining the appropriate level of postoperative care after TAAA surgery notwithstanding the potential for medico-legal complications.

Clinical assessment from the end of the bed will undoubtedly benefit from more comprehensive physiological testing. This is particularly the case for increasing numbers of patients with TAAA who are considered for endovascular rather than open surgery ${ }^{33}$. It is likely in the future treatment plans will incorporate both open and endovascular approaches for intervention and this may even be incorporated in a staged manner ${ }^{34}$.

\section{Conclusions}

These findings highlight the interpretive limitations associated with the subjective assessment of patient frailty with surgical risk classification underestimated in up to a third of patients compared to the more objective validated assessment of post-operative outcomes via CPET-derived CRF. For 'high-stakes' open TAAA surgery, the integration of CPET can improve perioperative risk assessment though further research is required to identify 'lower limits' of CRF below which operative intervention may be considered prohibitively risky. Surgeons also need to consider (pre-operative) exercise training as a modifiable component of multimodal prehabilitation strategies with the potential to augment CRF, reduce surgical risk and thus improve outcome.

\section{Acknowledgements}

The authors thank Susan Y. Green MPH for input.

\section{Author's Contributions}


All authors read and approved the final manuscript.

\section{Availability of data and materials}

The data sets used and analysed during the study are available from the corresponding author upon request.

\section{References}

1. Stokes JW, Wanderer JP, McEvoy MD. Significant discrepancies exist between clinician assessment and patient self-assessment of functional capacity by validated scoring tools during preoperative evaluation. Perioper Med (Lond). 2016;5:18.

2. Hubbard RE, Story DA. Patient frailty: the elephant in the operating room. Anaesthesia. 2014;69 Suppl 1:26-34.

3. Ganapathi AM, Englum BR, Hanna JM, Schechter MA, Gaca JG, Hurwitz LM, et al. Frailty and risk in proximal aortic surgery. J Thorac Cardiovasc Surg. 2014;147(1):186-91 e1.

4. Sepehri A, Beggs T, Hassan A, Rigatto C, Shaw-Daigle C, Tangri N, et al. The impact of frailty on outcomes after cardiac surgery: a systematic review. J Thorac Cardiovasc Surg. 2014;148(6):3110-7.

5. Carlisle J, Swart M. Mid-term survival after abdominal aortic aneurysm surgery predicted by cardiopulmonary exercise testing. Br J Surg. 2007;94(8):966-9.

6. Carlisle JB, Danjoux G, Kerr K, Snowden C, Swart M. Validation of long-term survival prediction for scheduled abdominal aortic aneurysm repair with an independent calculator using only pre-operative variables. Anaesthesia. 2015;70(6):654-65.

7. Rose GA, Davies RG, Appadurai IR, Lewis WG, Cho JS, Lewis MH, et al. Cardiorespiratory fitness is impaired and predicts mid-term postoperative survival in patients with abdominal aortic aneurysm disease. Experimental physiology. 2018;103(11):1505-12.

8. Hernandez-Vaquero D, Diaz R, Pascual I, Alvarez R, Alperi A, Rozado J, et al. Predictive risk models for proximal aortic surgery. J Thorac Dis. 2017;9(Suppl 6):S521-S5.

9. Bashir M, Shaw MA, Grayson AD, Fok M, Hickey GL, Grant SW, et al. Development and Validation of Elective and Nonelective Risk Prediction Models for In-Hospital Mortality in Proximal Aortic Surgery Using the National Institute for Cardiovascular Outcomes Research (NICOR) Database. Ann Thorac Surg. 2016;101(5):1670-6.

10. Williams JR. The Declaration of Helsinki and public health. Bulletin of the World Health Organization. $2008 ; 86(8): 650-2$.

11. Knuf KM, Maani CV, Cummings AK. Clinical agreement in the American Society of Anesthesiologists physical status classification. Perioper Med (Lond). 2018;7:14.

12. Rose GA, Adamson MJ, Davies RG, Appadurai IR, Bailey DM. High-intensity exercise training improves perioperative risk stratification in the high-risk patient. Physiological reports. 2020;May;8(9):e14409.

13. Rose GA, Davies RG, Davison GW, Adams RA, Williams IM, Lewis MH, et al. The cardiopulmonary exercise test grey zone; optimising fitness stratification by application of critical difference. British journal of anaesthesia. 2018;120(6):1187-94.

14. Wasserman K. Principles of exercise testing and interpretation: including pathophysiology and clinical applications. 5th ed ed. Philadelphia, Pa

London: Wolters Kluwer/Lippincott Williams \& Wilkins; 2012.

15. Beaver WL, Wassermen K, Whipp BJ. A new method for detecting anaerobic threshold by gas exchange. J Appl Physiol. 1986;60(6):8. 
16. Weber KT, Janicki JS. Cardiopulmonary exercise testing for evaluation of chronic cardiac failure. American Journal of Cardiology. 1985;55(2):A22-A31.

17. Older R, Smith R, Courtney B, Hone R. Preoperative Evaluation of Cardiac Failure and Ischemia in Elderly Patients by Cardiopulmonary Exercise Testing. Chest. 1993;104(3):701-4.

18. Nepogodiev D, Martin J, Biccard B, Makupe A, Bhangu A, Nepogodiev D, et al. Global burden of postoperative death. The Lancet. 2019;393(10170):401.

19. Pearse RM, Harrison DA, James P, Watson D, Hinds C, Rhodes A, et al. Identification and characterisation of the high-risk surgical population in the United Kingdom. Crit Care. 2006;10(3):R81.

20. Coselli JS, LeMaire SA, Preventza O, de la Cruz KI, Cooley DA, Price MD, et al. Outcomes of 3309 thoracoabdominal aortic aneurysm repairs. J Thorac Cardiovasc Surg. 2016;151(5):1323-37.

21. Chatterjee S, Casar JG, LeMaire SA, Preventza O, Coselli JS. Perioperative care after thoracoabdominal aortic aneurysm repair: The Baylor College of Medicine experience. Part 2: Postoperative management. J Thorac Cardiovasc Surg. 2021;161(2):699-705.

22. Etz CD, Di Luozzo G, Bello R, Luehr M, Khan MZ, Bodian CA, et al. Pulmonary complications after descending thoracic and thoracoabdominal aortic aneurysm repair: predictors, prevention, and treatment. Ann Thorac Surg. 2007;83(2):S870-6; discussion S90-2.

23. Coselli JS, Green SY, Price MD, Zhang Q, Preventza O, de la Cruz KI, et al. Spinal cord deficit after 1114 extent II open thoracoabdominal aortic aneurysm repairs. J Thorac Cardiovasc Surg. 2019.

24. Girardi LN, Rabotnikov Y, Avgerinos DV. Preoperative percutaneous coronary intervention in patients undergoing open thoracoabdominal and descending thoracic aneurysm repair. J Thorac Cardiovasc Surg. 2014;147(1):163-8.

25. Milewicz DM, Ramirez F. Therapies for Thoracic Aortic Aneurysms and Acute Aortic Dissections. Arteriosclerosis, thrombosis, and vascular biology. 2019;39(2):126-36.

26. Wagner AH, Zaradzki M, Arif R, Remes A, Muller OJ, Kallenbach K. Marfan syndrome: A therapeutic challenge for long-term care. Biochem Pharmacol. 2019;164:53-63.

27. Giske L, Stanghelle JK, Rand-Hendrikssen S, Strom V, Wilhelmsen JE, Roe C. Pulmonary function, working capacity and strength in young adults with Marfan syndrome. J Rehabil Med. 2003;35(5):221-8.

28. Hornsby WE, Norton EL, Fink S, Saberi S, Wu X, McGowan CL, et al. Cardiopulmonary Exercise Testing Following Open Repair for a Proximal Thoracic Aortic Aneurysm or Dissection. J Cardiopulm Rehabil Prev. 2020;40(2):108-15.

29. Gillis C, Wischmeyer PE. Pre-operative nutrition and the elective surgical patient: why, how and what? Anaesthesia. 2019;74 Suppl 1:27-35.

30. Shoemaker WC, Appel PL, Kram HB. Role of Oxygen Debt in the Development of Organ Failure Sepsis, and Death in High-Risk Surgical Patients. Chest. 1992;102(1):208-15.

31. Grant SW, Hickey GL, Wisely NA, Carlson ED, Hartley RA, Pichel AC, et al. Cardiopulmonary exercise testing and survival after elective abdominal aortic aneurysm repair. Br J Anaesth. 2015;114(3):430-6.

32. Wilson D, Jackson T, Sapey E, Lord JM. Frailty and sarcopenia: The potential role of an aged immune system. Ageing Res Rev. 2017;36:1-10.

33. Wang GJ, Jackson BM, Foley PJ, Damrauer SM, Goodney PP, Kelz RR, et al. National trends in admissions, repair, and mortality for thoracic aortic aneurysm and type B dissection in the National Inpatient Sample. J Vasc Surg. 2018;67(6):1649-58. 
34. Le Huu A, Coselli JS. Commentary: Aortic repair in the Great White North-endovascular or open, eh? J Thorac Cardiovasc Surg. 2021;161(2):528-9.

Table 1. Patient characteristics

\begin{tabular}{|c|c|}
\hline \multicolumn{2}{|l|}{ Demographics } \\
\hline Sample size (n) & 127 \\
\hline Male (n/\%):Female (n/\%) & $74 / 58: 53 / 42$ \\
\hline Age $(y)$ & $69 \pm 10$ \\
\hline $\operatorname{BMI}\left(\mathrm{kg} / \mathrm{m}^{2}\right)$ & $29 \pm 7$ \\
\hline \multicolumn{2}{|l|}{ Spirometry } \\
\hline FVC (\% predicted) & $95 \pm 19$ \\
\hline $\mathrm{FEV}_{1}(\%$ predicted $)$ & $92 \pm 22$ \\
\hline $\mathrm{FEV}_{1} / \mathrm{FVC}(\%$ predicted $)$ & $73 \pm 9$ \\
\hline \multicolumn{2}{|l|}{ CPET metrics } \\
\hline Peak workload (W) & $95 \pm 43$ \\
\hline Peak workload (\% predicted) & $85 \pm 29$ \\
\hline$V \mathrm{O}_{2 \text { PEAK }}(\mathrm{mL} / \mathrm{kg} / \mathrm{min})$ & $17.8 \pm 5.2$ \\
\hline$V \mathrm{O}_{2 \text { PEAK }}(\%$ predicted $)$ & $81 \pm 20$ \\
\hline$V_{\mathrm{E}} / V \mathrm{CO}_{2}$ slope $(\mathrm{AU})$ & $34 \pm 6$ \\
\hline OUES $\left[\left(\mathrm{mL} / \mathrm{min} \mathrm{O}_{2}\right) /\left(\mathrm{L} / \min V_{\mathrm{E}}\right)\right]$ & $1729 \pm 490$ \\
\hline$V \mathrm{O}_{2}-\mathrm{AT}>11 \mathrm{~mL} / \mathrm{kg} / \mathrm{min}(\mathrm{n} / \%)$ & $64 / 50$ \\
\hline$V \mathrm{O}_{2}-\mathrm{AT}<11 \mathrm{~mL} / \mathrm{kg} / \min (\mathrm{n} / \%)$ & $45 / 35$ \\
\hline$V \mathrm{O}_{2}$-AT indeterminate $(\mathrm{n} / \%)$ & $18 / 14$ \\
\hline
\end{tabular}

Values are mean $\pm \mathrm{SD}$; BMI, body mass index; FVC, forced vital capacity; $\mathrm{FEV}_{1}$, forced expiratory volume in one second; $V \mathrm{O}_{2 \mathrm{PEAK}}$, peak pulmonary oxygen uptake; $V \mathrm{E} / V \mathrm{CO}_{2}$, ventilatory equivalent for carbon dioxide; OUES, oxygen uptake efficiency slope; $V \mathrm{O}_{2}$-AT, pulmonary oxygen uptake at the anaerobic threshold.


Figure 1. Anatomical aspects and surgical approach to extent II thoracoabdominal repair.

A. The chest is entered through the sixth intercostal space. Left medial visceral rotation and circumferential division of the diaphragm enable exposure of the entire thoracoabdominal aorta. B. Left heart bypass (LHB) is commonly used to offload the heart from stressors of aortic surgery; LHB is initiated by placing a cannula in the left atrium via a left inferior pulmonary venotomy and then connecting it to the drainage line of the LHB circuit. After initiation, the proximal aortic clamp is placed. The distal aortic clamp is placed across the mid-descending thoracic aorta. The aortic segment between the two clamps is opened longitudinally using electrocautery. A stand-alone circuit to provide cold renal perfusion is prepared for later use. C. Following completion of the proximal anastomosis, the aorta is opened longitudinally to the aortic bifurcation. Crucial intercostal and lumbar arteries are reattached. Cold renal perfusion and selective visceral perfusion are provided to protect the visceral organs. 


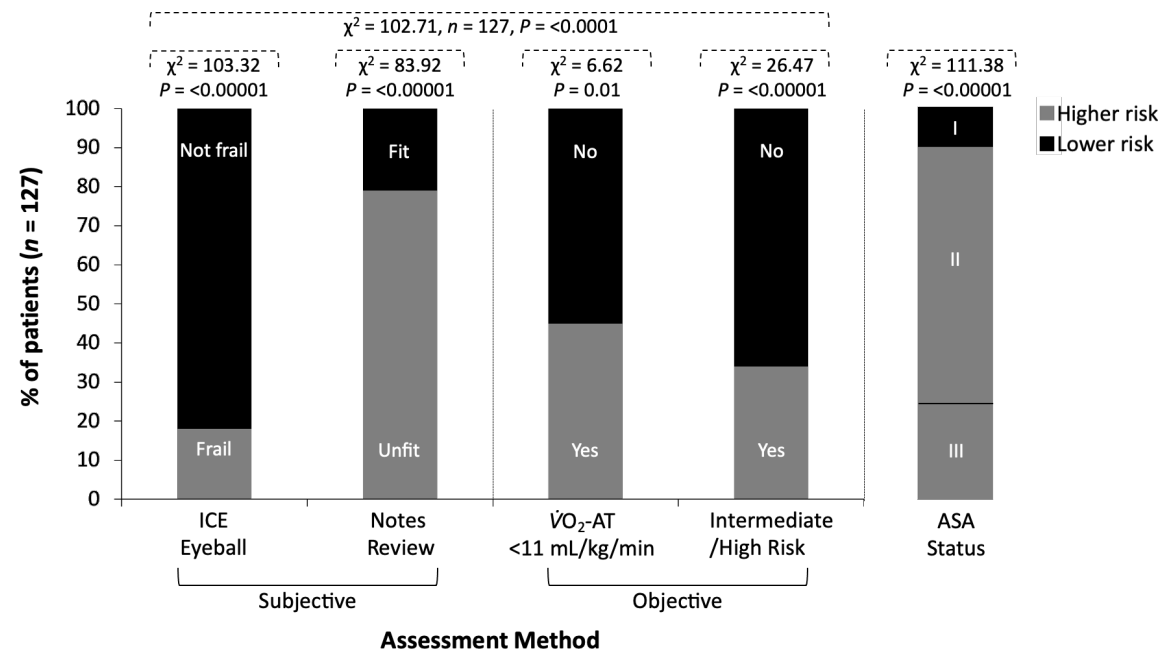

Figure 2. Differences in clinical risk classification according to patient assessment method.

ICE, initial clinical evaluation; ( $V \mathrm{O}_{2}$-AT) pulmonary oxygen uptake at the anaerobic threshold during cardiopulmonary exercise testing; ASA, American Society of Anaesthesiologists score (ASA I, normal healthy, ASA II, mild systemic disease, ASA III, severe systemic disease).
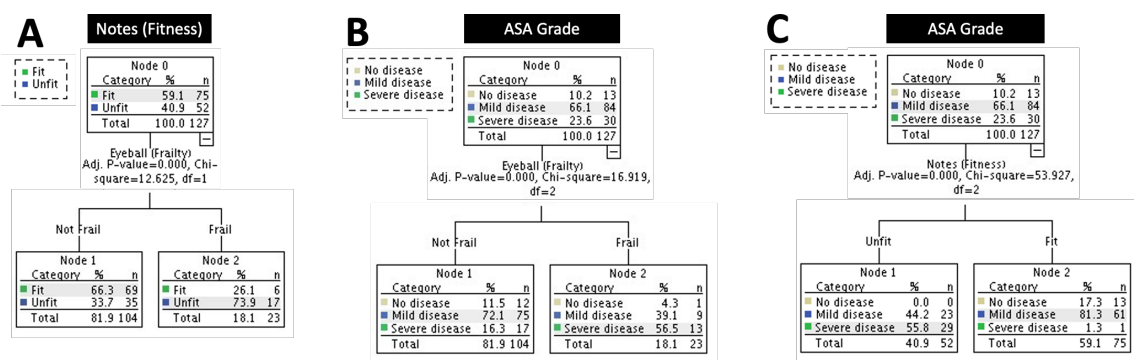

Figure 3. Comparison between different subjective methods of patient risk assessment.

ASA, American Society of Anaesthesiologists score (ASA I, normal healthy, ASA II, mild systemic disease, ASA III, severe systemic disease). 


\section{$\mathrm{VO}_{2}-\mathrm{AT}<11 \mathrm{~mL} / \mathrm{kg} / \mathrm{min}$}


Figure 4. Comparison of subjective assessment of patient risk (initial clinical evaluation (ICE) of frailty and notes-review of fitness) against risk defined by objective cardiopulmonary exercise testing (CPET) metrics.

$V \mathrm{O}_{2}$-AT, pulmonary oxygen uptake at the anaerobic threshold. See Methods for definition of low, intermediate and high risk. 